\title{
CAN EMPATHY LEAD TO EMOTIONAL EXHAUSTION IN TEACHERS? THE MEDIATING ROLE OF EMOTIONAL LABOR
}

\author{
MONIKA WRÓBEL \\ University of Lodz, Łódź, Poland \\ Institute of Psychology, Department of Psychology of Personality and Individual Differences
}

\begin{abstract}
Objectives: The present study was designed to examine the links between empathy, emotional labor (both surface and deep acting), and emotional exhaustion as well as determine if emotional labor mediates the relationship between empathy and emotional exhaustion in teachers. It was assumed that emotional labor can take two opposite directions (positive mood induction and negative mood induction). Thus, the additional aim of the study was to analyze the mediating role of mood regulation strategies in the relationship between empathy and emotional exhaustion. Materials and Methods: A sample of 168 teachers from Lódź and its surroundings completed a set of questionnaires: Emotional Labor Scale; Mood Regulation Scales, Maslach Burnout Inventory, and Empathic Sensitivity Scale. Results: The results provided mixed support for the hypotheses indicating that both types of emotional labor, negative mood induction and emotional exhaustion were positively intercorrelated. Moreover, deep acting was a significant mediator in the relationship between empathy and emotional exhaustion. The analyzed link was also mediated by negative mood induction, whereas positive mood induction did not emerge as a significant mediator. Conclusions: The study provided insight into the role of empathy and emotional labor in the development of teacher burnout. It also confirmed that deep acting and negative mood induction mediate the relationship between empathy and emotional exhaustion in teachers.
\end{abstract}

Key words:

Burnout, Emotional labor, Empathy, Teachers

\section{INTRODUCTION}

Nowadays it seems obvious that emotions play an important role in the workplace. This can be true especially in the case of teachers whose role is not only to teach, but also to establish and maintain a learning-friendly environment. In practice, it may mean showing enthusiasm while conducting classes, reacting with empathy to pupils' worries and needs, hiding fatigue and annoyance or displaying positive emotions even when pupils are being difficult and rude. Teachers have to educate and, at the same time, manage their own emotions to meet the expectations associated with their profession [1,2]. In other words, they perform emotional labor.

Emotional labor is a construct introduced in 1983 by Hochschild who defined it as the regulation of employee's emotions to comply with occupational or organizational norms [3]. Since Hochschild's pioneer research on flight attendants, several other professions have been investigated regarding the management of emotions at work. For example, it has been shown that emotional labor is

Research for this article was supported by a grant from University of Lodz, no. 545/043.

Received: October 19, 2012. Accepted: May 23, 2013.

Corresponding author: M. Wróbel, Department of Psychology of Personality and Individual Differences, Institute of Psychology, University of Lodz, Smugowa 10/12, 91-433 Łódź, Poland (e-mail: mwrobel@uni.lodz.pl). 
performed on a daily basis by nurses, police officers, retail sales, bank and hotel employees [4-8]. Recent research has also focused on teachers as "emotional laborers" [2,9-11]. It has been stressed that emotional involvement is an integral part of the teaching profession [1,12-16]. A significant majority of the teaching workforce is represented by women, which clearly corresponds with the fact that emotional labor is typical of those professions which are feminized [3,17].

However, when compared to other, especially commercial professions, teachers' emotional labor turns out to have some distinctive characteristics. Firstly, the interactions with pupils, in contrast to the interactions with clients of commercial services, are often long-term, repeated and intense. Research conducted on the representative sample of teachers from the Łódź voivodeship shows that pupils are very demanding to work with, because teachers are repeatedly exposed to their misbehavior. Although severe forms of problematic behavior in students (e.g. obscene language, verbal and physical abuse, truancy) are observed less often than its mild types (e.g. talking at improper times, not paying attention, cheating during tests), the latter ones occur frequently enough to have negative effects on teachers' functioning [18]. Not only do they interfere with the teaching process, but also seem to be the leading contributor to emotional exhaustion. For instance, it might be extremely difficult to control anger or irritation when interacting with students who ignore teachers' requests or tease other pupils. Additionally, some students may have special educational needs (SPE) which not only affect their ability to learn, but also attract a lot of teachers' attention. Teachers are expected to help these children overcome the barriers by providing them with adequate support, re-arranging the lessons or devoting some extra time to them. Thus, working with children with learning disabilities, emotional and behavioral difficulties, health problems or other SPE may be especially stressful and emotionally engaging [19-21].
Secondly, teachers - as opposed to other service professionals - perform emotional labor despite the lack of clear external motivators to do so. Teachers' remuneration is usually stable, independent of particular behaviors or accomplishments. Moreover, the emotional display rules imposed by schools are not as strict and precise as in case of other, especially commercial organizations. The deficiency of external rewards and weak control over teachers' emotions may increase their internal motivation to regulate their affective states at work $[22,23]$. This suggests that teachers may perform emotional labor due to their work ethics rather than organizational rules and regulations. Teaching as a job falls under the category of the socalled helping professions, which means that in the eyes of the society being a teacher is a mission rather than just a regular occupation. As a result, the public has extremely high expectations of teachers - they should always be kind, considerate and willing to help and never be tired or irritated $[15,16,24]$. The necessity of maintaining this image may strongly predispose teachers to emotional labor, and consequently, lead to psychological costs [16].

According to Hochschild [3] and Grandey [17], emotional labor is one of the most important stressors in service professions. However, the analysis of Polish literature leads to the conclusion that so far this factor has not gained adequate attention as a potential cause of teacher burnout. This gap needs to be filled because of at least two reasons. Firstly, the conditions in which Polish teachers perform their jobs are culturally unique (e.g. low socio-economic status, unsatisfactory physical characteristics of the work environment, adverse employee selection [16,25]), which makes it difficult to apply the results of research conducted abroad to Polish conditions. Secondly, the results of studies on Polish teachers provide more and more support for the importance of psycho-social factors in the development of burnout $[16,25,26]$. It has been shown that strained relationships with students and their parents as well as with supervisors and colleagues may be one of 
the most important stressors in the teachers' work environment [25]. These relations are very emotional in nature [13] and thus, to a large extent, linked to teachers' emotion management skills. Therefore, Polish research to date provides excellent context for the analysis of the role of empathy and emotional labor in the development of burnout among teachers.

Although emotional labor has been conceptualized in a variety of ways, the majority of researchers differentiate between two main strategies [3,17,27-29]. First of them, called surface acting, refers to the modification of emotional expression without changing the inner states. For instance, a teacher who feels angry or sad may fake a smile to hide his/her negative feelings in front of the pupils. The second strategy, referred to as deep acting, involves the change of an employee's inner feelings in order to arouse the desired emotions. For example, a teacher, who feels angry or sad, may recall his/her past experience to cheer himself/herself up and, as a result, display positive emotional expression in front of the students. Although both surface and deep acting are aimed at evoking the organizationally required emotions, they achieve this aim differently: the former focuses exclusively on the displayed emotions (namely, emotional expression), whereas the latter requires managing both the displayed and the felt emotions [3].

Previous research has indicated that emotional labor may be associated with negative consequences for the employees' psychological functioning, such as burnout, job dissatisfaction, and high level of stress [17,27,30-32]. The analysis of the literature shows that these problems are related to surface acting in particular, due to the fact that inhibition or suppression of the "true" emotions require more energy and resources than displaying emotions evoked through deep acting strategy [33-35]. Some researchers even claim that the consequences of deep acting may not only be less negative, but also beneficial for the employees' well-being $[31,32,36]$. For example, deep acting was found to be positively associated with job satisfaction and a sense of personal accomplishment [4,27,32,37,38].

The differences in the consequences of applying the surface and deep acting can be observed in the case of the most prevalent cost of emotional labor, namely emotional exhaustion. Surface acting has been proved to correlate positively with it $[31,33,39-41]$, whereas the relation between emotional exhaustion and deep acting remains unclear. On the one hand, Brotheridge and Grandey [31] theorize that emotion regulation techniques used during deep acting require less energy and resources than the ones used during surface acting, which suggests that they should also be less emotionally exhausting. On the other hand, the meta-analysis conducted by Bono and Vey [42] indicated that both surface and deep acting are positively related to emotional exhaustion, but in case of the latter this correlation is weaker. Polish research on the relationship between emotional labor and emotional exhaustion has also brought inconsistent findings - the relationship was confirmed only in the case of surface acting [43]. Thus, based on prior studies, we expected that surface acting would be positively related to emotional exhaustion, but we had no specific hypotheses regarding the link between emotional exhaustion and deep acting.

One of the reasons behind the inconclusive findings may lie in the direction of the emotion regulation strategies involved in emotional labor. Usually, the management of emotions at work is associated with the inhibition of negative feelings/expressions and the induction of positive ones, because it is thought that clients prefer smiling and happy employees over sad and angry ones. However, there are some professions in which the direction of the regulation seems to be opposite - for example, ticket inspectors or undertakers may lower their mood when with their clients [44]. It is quite plausible that in the case of teachers, emotional labor may take both directions - for instance, a teacher may put on a positive expression to show his/her enthusiasm while conducting 
classes or assume a negative one to maintain classroom discipline or to show compassion towards worried or sad students. Therefore, we predicted that emotional labor would be positively related to both positive and negative mood induction strategies. In other words, the more emotional labor a teacher performs, the more frequently both mood regulation strategies are used. Since the process of mood induction may refer to inner feelings as well as external expressions, we expected that this prediction will apply to both, the surface and deep acting. The question remains, however, whether both of the two mood regulation techniques (positive mood induction and negative mood induction) are associated with emotional exhaustion in the same way. It is possible that emotional labor involving positive mood induction is less detrimental to the teachers' functioning than emotional labor based on negative mood induction.

It should also be noted that not all teachers perform emotional labor and experience emotional exhaustion. The reason for it may lie in individual traits $[24,45]$. For instance, some teachers are more empathic than others and, thus, more predisposed to perform emotional labor. Empathy is an integral part of the teacher's role, but some teachers may lack this ability [46,47]. Hence, it is important to develop it in order to enable teachers to interpret and react to pupils' feelings and needs properly [47]. Positive as it may seem, high level of empathy may create some problems. It is possible that teachers who are very responsive to their students' emotions will suffer from emotional exhaustion. However, to our knowledge, the studies on this relationship in teachers are scarce [45], and that is why we decided to fill this gap. We predicted that empathy would lead to emotional exhaustion, because empathic teachers would engage in emotional labor more often than their nonempathic colleagues. In other words, surface and deep acting would mediate the relationship between empathy and emotional exhaustion. Moreover, having assumed

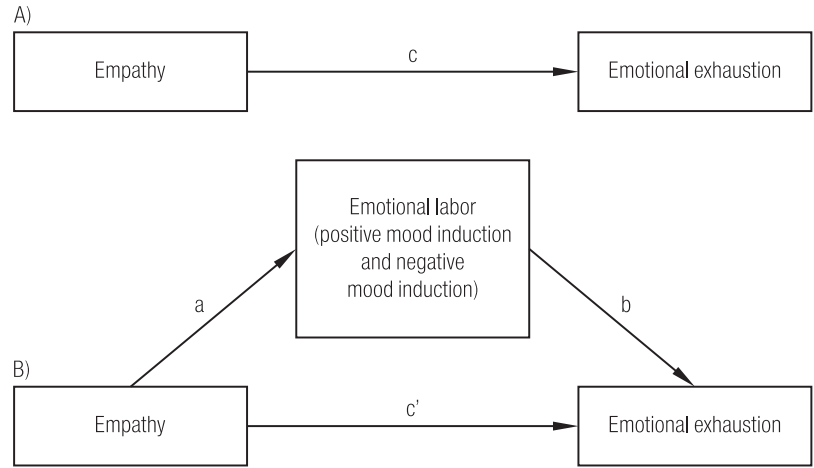

A - direct effect of empathy on emotional exhaustion.

$\mathrm{B}$ - indirect effect of empathy on emotional exhaustion through emotional labor.

Fig. 1. The theoretical model of the relationships between empathy, emotional labor, and emotional exhaustion

that emotional labor may take two different directions, we expected that positive mood induction and negative mood induction will also mediate the empathy and emotional exhaustion link. Figure 1 depicts the hypothesized relationships.

Summing up, the purpose of the present study was to analyze the relationships between empathy, emotional labor (both surface and deep acting), and emotional exhaustion in teachers. The study was also aimed at verifying if emotional labor mediates the relationship between empathy and emotional exhaustion. Since we assumed that emotional labor can take two opposite directions (positive mood induction and negative mood induction), we also planned to determine if these two mood regulation strategies mediate the link between empathy and emotional exhaustion.

\section{MATERIALS AND METHODS}

\section{Participants}

The sample consisted of 209 teachers working in schools located in Łódź and its surroundings (Zgierz, Gieczno, Łowicz, Bielawy, and Łyszkowice). The schools were selected on the basis of accessibility, thus the sample was 
not representative of the population of teachers from the Łódź area. Due to the incomplete data, some subjects were excluded from further analysis. The final sample comprised 168 teachers. Most of them worked in primary schools (44\%), lower secondary schools (29.2\%) and high schools $(8.3 \%)$. Teachers working in different types of schools made up $12 \%$ of the sample $(6.5 \%$ did not provide the information about the type of school they worked in). The majority of the subjects were females (81\%), which reflects the percentage of women employed in the Polish educational sector [48]. The subjects' age ranged from 23 to 64 years with the mean at $41.70(\mathrm{SD}=9.41)$, whereas their work experience covered from 6 months to 40 years $(M=17.32 ; \mathrm{SD}=9.43)$. They declared that they spent from 10 to 70 hours a week performing their job activities (including the work they did at home; $\mathrm{M}=39.45$; $\mathrm{SD}=9.81$.

\section{Measures}

The level of deep and surface acting was assessed with the Emotional Labor Scale (ELS) [29], which is a 10-item selfreport measure. The respondents are asked to indicate to what extent they engage in various deep and surface acting processes. The items are scored on a 7-point scale, ranging from "seldom" to "always". The ELS is characterized by high internal consistency (Cronbach's $\alpha$ for the deep acting subscale from 0.81 to 0.83 ; for the surface acting subscale from 0.84 to 0.87 ).

The tendency to use two mood regulation strategies positive mood induction and negative mood induction was measured with the Mood Regulation Scales (MRS) by Wojciszke [49]. MRS is a paper-and-pencil tool aimed at assessing the frequency of engaging in different mood regulation techniques. The items are scored on a 5-point scale from "never" to "always". Both subscales (positive mood induction and negative mood induction) have good internal consistency (Cronbach's $\alpha$ s equal to 0.81 and 0.90 , respectively).
Emotional exhaustion, treated as one of the dimensions of the burnout syndrome, was measured with a Polish adaptation of Maslach Burnout Inventory (MBI) by Pasikowski [50]. The MBI consists of 22 items. The subjects are asked to indicate on a 7-point scale how often they experience various burnout symptoms (from "never" to "everyday"). The internal consistency of the emotional exhaustion subscale (9 items) is satisfactory (Cronbach's $\alpha=0.86$ ).

The level of empathy was assessed with the Empathic Sensitivity Scale (ESS) [51], which measures the emotional and cognitive aspects of empathy proposed by Davis [52]. The respondents are asked to indicate on a 5-point scale to what extent they agree or disagree with 28 statements (from "strongly disagree" to "strongly agree"). Although the scale consists of 3 subscales (emphatic concern, personal distress and perspective taking), when the data was subjected to the principal components analysis, it turned out that its 3-dimensional structure was not confirmed. The analysis revealed six components with eigenvalues exceeding 1 (with "emotional" and "cognitive" items loading on common factors). Still, the inspection of the screeplot showed a clear cut after the first component. The factor accounted for $30.73 \%$ of the variance and was characterized by acceptable internal consistency (Cronbach's $\alpha=0.80$ ).

\section{Procedure}

The research was conducted at the end of October and the beginning of November 2011. The participants received a set of questionnaires directly from the researcher who informed them that the data was collected anonymously and only for scientific purposes. The questionnaires were filled in within 2 weeks and then returned to the researcher in closed envelopes. Unfortunately, the response rate could not be calculated, because it was not systematically recorded how many teachers refused to participate. Still, $82 \%$ of the teachers who agreed to fill in the questionnaires gave them back. 


\section{RESULTS}

Table 1 presents means, standard deviations and zero-order correlations between the analyzed variables. According to the predictions, emotional exhaustion turned out to be positively related to surface acting and negative mood induction. Its relationship with deep acting was also positive. Moreover, in line with the expectations, the correlation between emotional exhaustion and empathy almost reached the level of statistical significance (10\% level [see 53,54]). Empathy was also positively associated with deep acting and both mood induction strategies. Still, the correlation between empathy and surface acting was not confirmed. Additionally, whereas negative mood induction correlated positively with both types of emotional labor, positive mood induction turned out to be related only to deep acting (this link reached only the $10 \%$ significance level). Thus, the correlation coefficients provided support for the majority, but not all of the expected associations. Above all, they confirmed positive intercorrelations between both types of emotional labor, negative mood induction and emotional exhaustion.

To verify the predictions regarding the role of emotional labor in the relationship between empathy and emotional exhaustion, multiple mediation analyses with the use of SPSS Macro INDIRECT [55] were conduced. They followed the model depicted in Figure 1. The c path refers to the direct relationship between the predictor and the outcome. The a path depicts the association between the predictor and the potential mediator, whereas the $\mathrm{b}$ path - the relationship between the mediator and the dependent variable. The c path illustrates the indirect effect of the independent variable on the dependent variable while including the mediator in the equation. All mediation analyses was based on bootstrapping [55,56], which is more robust to deviations from normality [57]. The number of bootstrap samples was 2000. Data used in the analyses were not standardized. Following the suggestions of Hayes [58], we treated the indirect effect as statistically significant when the $95 \%$ bias corrected confidence interval did not include zero.

Due to the fact that deep and surface acting were strongly correlated (see Table 1), they were entered into two separate models to avoid the problem of multicollinearity between the proposed mediators. Figure 2 presents the results of the first of multiple mediation analyses. It should be noted that the links illustrated by the $\mathrm{c}$ and $\mathrm{b}$ paths reached only the $10 \%$ statistical significance level. Still, the analysis of the bootstrap results for indirect effects indicated that, in line with the predictions, deep acting was a significant mediator in the relationship between

Table 1. Descriptive statistics and zero-order correlations for study variables

\begin{tabular}{|c|c|c|c|c|c|c|c|}
\hline \multirow{2}{*}{ Variables } & \multicolumn{2}{|c|}{ Descriptives } & \multicolumn{5}{|c|}{ Pearson's correlation coefficients } \\
\hline & $\mathrm{M}$ & SD & 1 & 2 & 3 & 4 & 5 \\
\hline 1. Emotional exhaustion & 13.94 & 9.35 & - & & & & \\
\hline 2. Empathy & 97.92 & 10.65 & $0.14^{\wedge}$ & - & & & \\
\hline 3. Deep acting & 13.93 & 5.11 & $0.17^{*}$ & $0.17^{*}$ & - & & \\
\hline 4. Surface acting & 15.62 & 6.60 & $0.25^{* *}$ & 0.08 & $0.73^{* * *}$ & - & \\
\hline 5. Negative mood induction & 37.28 & 11.15 & $0.37^{* * *}$ & $0.44^{* * *}$ & $0.27^{* *}$ & $0.26^{* *}$ & - \\
\hline 6. Positive mood induction & 56.38 & 8.88 & -0.11 & $0.23^{* *}$ & $0.14^{\wedge}$ & -0.06 & $0.15^{\wedge}$ \\
\hline
\end{tabular}

$\mathrm{M}$ - mean.

$\mathrm{SD}$ - standard deviation.

^ $\mathrm{p}<0.1 ;{ }^{*} \mathrm{p}<0.05 ;{ }^{* *} \mathrm{p}<0.01 ;{ }^{* * *} \mathrm{p}<0.001$. 
A)
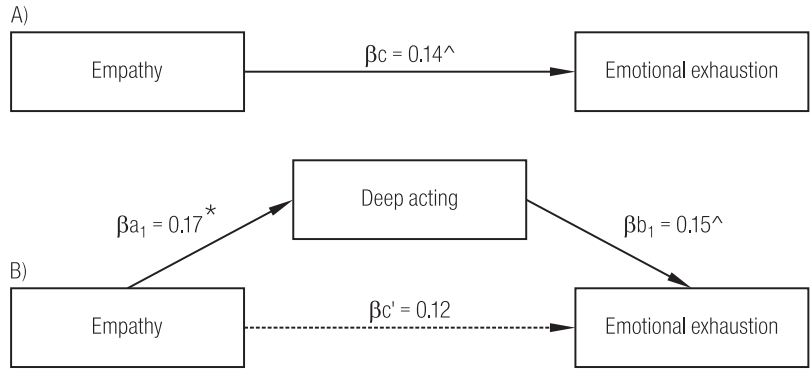

A - direct effect of empathy on emotional exhaustion.

$\mathrm{B}$ - indirect effect of empathy on emotional exhaustion through deep acting.

^ $\mathrm{p}<0.1 ; * \mathrm{p}<0.01 ; * * \mathrm{p}<0.001$.

The dotted line signifies the relationship with $\mathrm{p}$ value $>0.1$.

Fig. 2. The relationships between empathy, deep acting and emotional exhaustion

empathy and emotional exhaustion, 95\% CI: 0.001-0.086. Including it in the model significantly reduced the strength of the association between the predictor and the outcome (c' path). The model reached statistical significance $F(2,165)=3.73, \mathrm{p}<0.05$, but explained only $3.17 \%$ of the variance. The analogous model, in which surface acting was entered as a mediator, turned out to be insignificant. Finally, having assumed that emotional labor in teachers may take two different directions, we decided to analyze
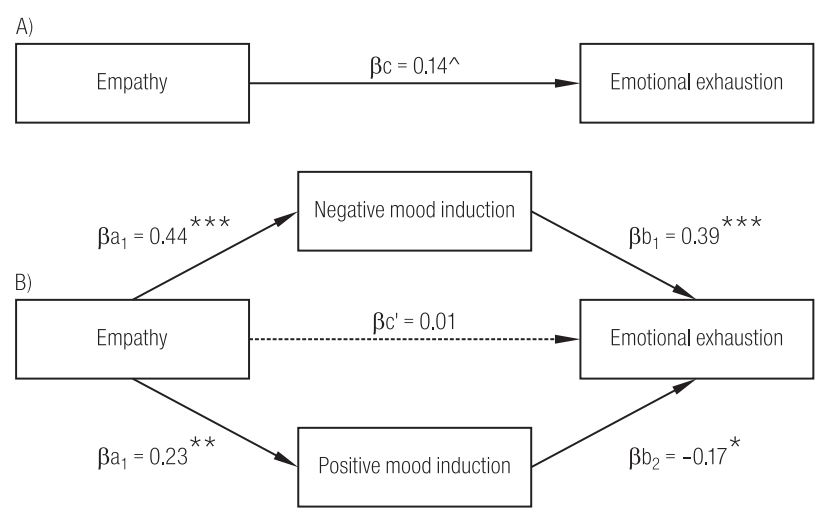

A - direct effect of empathy on emotional exhaustion.

$\mathrm{B}$ - indirect effect of empathy on emotional exhaustion through mood regulation strategies.

Other abbreviations as in Figure 2.

Fig. 3. The relationships between empathy, mood regulation strategies and emotional exhaustion the mediating role of the positive and negative mood induction strategies in the relationship between empathy and emotional exhaustion. Figure 3 depicts the results of the multiple mediation analysis with mood regulation strategies as potential mediators. As expected, the total indirect effect was significant, 95\% CI: 0.056-0.264. However, while negative mood induction emerged as a significant mediator in the relationship between empathy and emotional exhaustion, 95\% CI: 0.097-0.276, positive mood induction's effect did not obtain the level of statistical significance, $95 \%$ CI: $-0.086-0.006$. This model also reached statistical significance $F(3,164)=15.25, \mathrm{p}<0.001$ and explained $20.39 \%$ of the variance.

\section{DISCUSSION AND CONCLUSIONS}

The aim of the present study was to analyze the relationships between empathy, emotional labor, and emotional exhaustion in teachers. We also planned to verify if emotional labor as well as positive and negative mood induction strategies mediate the relationship between empathy and emotional exhaustion. We expected that empathic teachers would engage in the management of emotions at work to a greater extent than their non-empathic colleagues, and thus, would experience higher emotional exhaustion.

As hypothesized, emotional exhaustion was positively related to surface acting, which is in concordance with the previous findings [31,33,39-41]. We also found a positive, but weaker correlation between emotional exhaustion and deep acting, which corresponds with the results of the meta-analysis conducted by Bono and Vey [42]. This pattern of results, also confirmed by beta coefficients observed in mediation analyses ${ }^{1}$, indicates that not only faking emotions, but also changing inner feelings for the sake of organizational display rules may lead to negative consequences

\footnotetext{
${ }^{1}$ Regression coefficients obtained in mediation analyses also indicated that both surface acting $(\beta=0.24 ; p=0.002)$ and deep acting $(\beta=0.15 ; p=0.052)$ were positively linked to emotional exhaustion.
} 
(although to a lesser extent). One of the possible explanations may be that both surface and deep acting require constant monitoring and regulating of one's expression/ feelings, which in the long run may be emotionally exhausting. This finding corresponds to other Polish research on potential stressors in teachers' work environment indicating that psycho-social factors may be significant contributors to teacher burnout $[15,25]$.

The analysis of the role of mood induction strategies showed that only lowering the mood was associated with emotional exhaustion. It suggests that what teachers may find really emotionally exhausting, is not evoking positive feelings or expressions, but arousing negative ones when with their students. The results of mediation analyses confirm this reasoning. They showed that although the relationship between empathy and emotional exhaustion was mediated by negative mood induction, positive mood induction did not emerge as a statistically significant mediator. One of the reasons may be that it is a natural human tendency to maximize positive and minimize negative experience [59]. Thus, the regulation which takes the opposite direction may be particularly demanding or overloading. Another explanation may lie in the fact that there are additional variables responsible for the observed outcomes. For instance, both mood regulation strategies relate to individual traits associated with positive and negative affectivity - negative mood induction correlates positively with neuroticisms and negatively with extraversion, whereas positive mood induction is positively linked to extraversion [49]. Such traits are also related to burnout $[24,45,60]$ and empathy $[45,47,51]$, which suggests that teacher's personality and temperamental traits should be controlled for in future research.

Including empathy in the research model yielded some interesting findings about the possible individual determinants of emotional labor and its consequences. To the author's knowledge, the role of empathy in the process of deep or surface acting has not been extensively explored in empirical studies. The present research demonstrated that deep acting may be motivated by a high level of empathy, but the determinants of surface acting remain unknown. This pattern of results seems clear, especially when we realize that the term "empathy" refers not only to knowing what the other person is feeling, but also to experiencing emotions that match another person's emotional states [52,61]. In other words, since empathy is about feeling rather than just displaying emotions, it goes together with deep acting, but it does not relate to surface acting. Still, it is worth mentioning again that deep-level emotional labor may be beneficial for teachers only as long as it demands maximizing positive (not negative) feelings. This suggests that empathy, valuable though it may seem, sometimes may trigger the mechanism that leads to emotional exhaustion. This finding is worth further exploration, because studies to date have not confirmed the association between empathy and emotional exhaustion. For instance, in Kliś and Kossewska's research [45] empathy turned out to be related only to the two remaining dimensions of the burnout syndrome (i.e. depersonalization and a diminished sense of personal accomplishment). Thus, based on the findings regarding the role of empathy in the management of emotions at work, researchers should continue to explore how sensitivity to others' feelings (especially the negative ones) translates into emotional labor and its consequences.

Summing up, the study provided valuable insight into the role of empathy and emotional labor in the development of emotional exhaustion. From the applied perspective, the present results can be useful in preventing or reducing emotional exhaustion among teachers. The finding that surface acting may be particularly emotionally exhausting suggests that the interventions aimed at minimizing teacher burnout should focus on the mood regulation skills. As it was stated earlier, teaching involves immense amounts of emotional labor and for that reason it is impossible for teachers not to use their emotions at work $[12,13]$. 
Therefore, they should be taught how to effectively evoke necessary emotions without negative consequences of this process. This skill can be especially useful when interacting with students who misbehave, because such interactions often lead to negative emotions and require a great deal of emotional regulation. Still, whether these interactions will contribute to emotional exhaustion or not depends on the way a teacher will interpret a student's behavior. As Chang [12] pointed out, teachers do not experience burnout because of students' behavior itself, but because of teachers' appraisals. For instance, some teachers may interpret students' misbehavior personally. As a result, they may react with such unpleasant feelings that they might be extremely difficult to mask. In this case, surface acting may be extremely emotionally exhausting. It is essential to help teachers better understand how their feelings are triggered. This will make it possible for them to start managing their emotions before these feelings are too intense to hide. In other words, teachers should be trained in decoding their own emotions as well as in using such mood regulation techniques which are more effective and less detrimental to psychological functioning than surface acting (for instance, cognitive re-interpretation [17,62,63]). The training should also focus on the role of empathy in teaching. It has been shown that although empathic teachers do not use surface acting, they may feel emotionally drained due to deep-level emotional labor, especially when it involves negative mood induction. It is possible that empathic teachers fully engage in interactions with worried, dejected or anxious students and thus, suffer from emotional exhaustion. Therefore, it is vital to help teachers understand that although empathy is one of their key competencies [46,47], it may also lead to negative consequences.

Finally, some limitations of the research should be noted. Firstly, all the data were obtained from a sample of teachers who represented several school types. It is possible that the requirements regarding emotional labor differ according to the type of the institution the teachers work in. Also, since we selected the schools on the basis of accessibility, the sample was not completely random. Future research attempts should take these facts into consideration. Additionally, all variables were measured with self-report methods, which provide information that may be inaccurate. Some teachers might have tried to present themselves in a better light (for example by not admitting to faking emotions), so it is necessary to control for social desirability variable in the future studies. Finally, this study was cross-sectional and correlational, and so neither causality nor directionality between the variables can be inferred. With regard to this limitation, we recommend longitudinal studies, since they offer a better understanding of such gradually developing processes as emotional exhaustion.

\section{REFERENCES}

1. Cheung F, Tang CSK, Tang S. Psychological capital as a moderator between emotional labor, burnout, and job satisfaction among school teachers in China. Int J Stress Manag. 2011;18(4):348-71, http://dx.doi.org/10.1037/a0025787.

2. Philip A, Schüpbach H. Longitudinal effects of emotional labour on emotional exhaustion and dedication of teachers. J Occup Health Psychol. 2010;15(4):494-504, http://dx.doi. org/10.1037/a0021046.

3. Hochschild AR. The Managed Heart. Commercialization of Human Feeling. Berkeley: University of California Press; 1883.

4. Chou HY, Hecker R, Martin A. Predicting nurses' well-being from job demands and resources: A cross-sectional study of emotional labour. J Nurs Manag. 2012;20(4):502-11, http:// dx.doi.org/10.1111/j.1365-2834.2011.01305.

5. Gray B. Emotional labour, gender and professional stereotypes of emotional and physical contact, and personal perspectives on the emotional labour of nursing. J Gender Stud. 2010;19(4):349-60, http://dx.doi.org/10.1080/09589236. 2010.514207. 
6. Moon TW,HurWM.Emotionalintelligence, emotionalexhaustion, and job performance. Soc Behav Pers. 2011;39(8):108796, http://dx.doi.org/10.2224/sbp.2011.39.8.1087.

7. Qin L, Shi X, Hui J. Emotional Labor Strategies, Emotional Exhaustion, and Turnover Intention: An Empirical Study of Chinese Hotel Employees. J Hum Resour Hosp Tour. 2012;11(2):87-105, http://dx.doi.org/10.1080/15332845. 2012.648837.

8. Schaible LM, Gecas V. The impact of emotional labor and value dissonance on burnout among police officers. Police Q 2010;13(3):316-41, http://dx.doi.org/10. 1177/1098611110373997.

9. Näring G, Briët M, Brouwers A. Beyond demand-control: Emotional labour and symptoms of burnout in teachers. Work Stress. 2006;20(4):303-15, http://dx.doi. org $/ 10.1080 / 02678370601065182$.

10. Sutton RE, Wheatley KF. Teachers' emotions and teaching: A review of the literature and directions for future research. Educ Psychol Rev. 2003;15:327-58, http://dx.doi. org/10.1023/A:1026131715856.

11. Zapf D, Holtz M. On the positive and negative effects of emotion work in organizations. Eur J Work Organ Psychol. 2006;15(1):1-28, http://dx.doi.org/10.1080/ 13594320500412199.

12. Chang M. An appraisal perspective of teacher burnout: Examining the emotional work of teachers. Educ Psychol Rev. 2009;21(3):193-218, http://dx.doi.org/10.1007/s10648009-9106-y.

13. Hargreaves A. The emotional practice of teaching. Teach Teach Educ. 1998;14(8):835-54, http://dx.doi.org/10.1016/ s0742-051x(98)00025-0.

14. Nias J. Thinking about feeling: the emotions in teaching. Camb J Educ 1996;26(3):293-306, http:/dx.doi. org/10.1080/0305764960260301.

15. Pyżalski J, Merecz D. Introduction. In: Pyżalski J, Merecz D, editors. [Psychosocial work conditions of Polish teachers. Between burnout and engagement]. Kraków: Oficyna Wydawnicza Impuls; 2010. p. 7-11. Polish.
16. Sęk H. [Burnout in teachers. Determinants and possibilities of prevention]. In: Sęk H, editor. [Burnout. Causes and prevention]. Warszawa: Polish Scientific Publishers PWN; 2011. p. 149-67. Polish.

17. Grandey AA. Emotional regulation in the workplace: A new way to conceptualize emotional labor. J Occup Health Psychol. 2000;5(1):95-110, http://dx.doi.org/10.1037//10768998.5.1.95.

18. Pyżalski J. [Teachers' psychosocial burdens at work resulting from student misbehavior]. Med Pr. 2008;59(4):307-13. Polish.

19. Antoniou AS, Polychroni F, Walters B. Sources of stress and professional burnout of teachers of special educational needs in Greece. Paper presented at International Special Education Congress 2000 [cited 2013 Mar 18]. Available from http:// www.isec2000.org.uk/abstracts/papers_p/polychroni_1.htm.

20. Male DB, May D. Research Section: Stress, Burnout and Workload in Teachers of Children with Special Educational Needs. Br J Spec Educ. 1997;24(3):133-40, http://dx.doi. org/10.1111/1467-8527.t01-1-00029.

21. Mackenzie S. It's been a bit of a rollercoaster': Special educational needs, emotional labour and emotion work. Int J Inclus Educ. 2012;16(10):1067-82, http://dx.doi.org/10. 1080/13603116.2010.538869.

22. Richer SF, Vallerand RJ. Supervisors' interactional styles and subordinates' intrinsic and extrinsic motivation. J Soc Psychol. 1995;135(6):707-22, http://dx.doi.org/10.1080/0022 4545.1995.9713974.

23. Vansteenkiste M, Simons J, Lens W, Sheldon KM, Deci EL. Motivating learning, performance, and persistence: The synergistic effects of intrinsic goal contents and autonomysupportive contexts. J Pers Soc Psychol. 2004;87(2):46-260, http://dx.doi.org/10.1037/0022-3514.87.2.246.

24. Kijowska I. [The role of personality factors in explaining teacher burnout]. In: Czajkowska-Ziobrowska D, Zduniak A, editors. [Education for safety: regional safety, educational challenges]. Poznań: Wydawnictwo Wyższej Szkoły Bezpieczeństwa; 2008. p. 266-76. Polish. 
25. Pyżalski J. [The consequences of the influence of work conditions on Polish teachers]. In: Pyżalski J, Merecz D, editors. [Psychosocial work conditions of Polish teachers. Between burnout and engagement]. Kraków: Oficyna Wydawnicza Impuls; 2010. p. 31-46. Polish.

26. Merecz D. [Psychosocial characteristics of work]. In: Pyżalski J, Merecz D, editors. [Psychosocial work conditions of Polish teachers. Between burnout and engagement]. Kraków: Oficyna Wydawnicza Impuls; 2010. p. 23-30. Polish.

27. Brotheridge CM, Lee RT. Testing a conservation of resources model of the dynamics of emotional labor. J Occup Health Psychol. 2002;7(1):57-67.

28. Diefendorff JM, Croyle MH, Gosserand RH. The dimensionality and antecedents of emotional labor strategies. J Vocat Behav. 2005;66:339-59, http://dx.doi.org/10.1016/ j.jvb.2004.02.001.

29. Kruml SM, Geddes D. Exploring the dimensions of emotional labor: The hearth of Hochschild's work. Manag Commun Q. 2000;14(1):8-49, http://dx.doi.org/10. 1177/0893318900141002.

30. Beal DJ, Trougakos JP, Weiss HM, Green SG. Episodic processes in emotional labor: Perceptions of affective delivery and regulation strategies. J Appl Psychol. 2006;91(5): 105365, http://dx.doi.org/10.1037/0021-9010.91.5.1053.

31. Brotheridge CM, Grandey AA. Emotional labor and burnout: comparing two perspectives of "people work". J Vocat Behav. 2002;60(1):17-39, http://dx.doi.org/10.1006/ jvbe.2001.1815.

32. Grandey AA. When "the show must go on": Surface and deep acting as determinants of emotional exhaustion and peer-rated service delivery. Acad Manage J. 2003;46(1): 86-96, http://dx.doi.org/10.2307/30040678.

33. Glomb TM, Tews MJ. Emotional labor: A conceptualization and scale development. J Vocat Behav. 2004;64(1):1-23, http://dx.doi.org/10.1016/S0001-8791(03)00038-1.

34. Morris AJ, Feldman DC. The dimensions, antecedents, and consequences of emotional labor. Acad Manage Rev. 1996;21(4):986-1010.
35. Szczygieł D, Bazińska R, Kadzikowska-Wrzosek R, Retowski S. [Emotional labour in service roles - conceptualization, theories and research]. Psychol Spol. 2009;3(11):155-66. Polish.

36. Hülsheger UR, Schewe AF. On the costs and benefits of emotional labor: A meta-analysis of three decades of research. J Occup Health Psychol. 2011;16(3):361-89, http:/ dx.doi.org/10.1037/a0022876.

37. Côté S, Morgan LM. A longitudinal analysis of the association between emotion regulation, job satisfaction, and intentions to quit. J Organ Behav. 2002;23(8):947-62, http:// dx.doi.org/10.1002/job.174.

38. Yang F, Chang C. Emotional labour, job satisfaction and organizational commitment amongst clinical nurses: A questionnaire survey. Int J Nurs Stud. 2008;45(6):879-8, http:/ dx.doi.org/10.1016/j.jinurstu.2007.02.001.

39. Ashforth BE, Humphrey RH. Emotional labor in service role: The influence of identity. Acad Manage Rev. 1993;18(1): 88-115.

40. Zammuner VL, Galli C. Wellbeing: Causes and consequences of emotion regulation in work settings. Int Rev Psychiatr. 2005;17(5):355-64, http://dx.doi. org/10.1080/09540260500238348.

41. Totterdell P, Holman D. Emotion regulation in customer service roles: testing a model of emotional labor. J Occup Health Psychol. 2003;8(1):55-73, http://dx.doi. org/10.1037/1076-8998.8.1.55.

42. Bono JE, Vey MA. Toward understanding emotional management at work: A quantitative review of emotional labor research. In: Härbel CEJ, Zerbe WJ, Ashkanasy NM, editors. Emotions on organizational behavior. Mahwah, NJ: Lawrence Erlbaum; 2005. p. 213-33.

43. Bazińska R, Kadzikowska-Wrzosek R, Retowski S, Szczygieł D. [Emotional labour strategies - construction and construct validity of Emotional Labour]. In: Zawadzka AM, editor. [Psychology of organizational management]. Warszawa: Polish Scientific Publishers PWN; 2010. p. 17095. Polish. 
44. Putnam LL, Mumby DK. Organizations, emotions, and the myth of rationality. In: Fineman S, editor. Emotion in organizations. London: Sage; 1993. p. 36-57.

45. Kliś M, Kossewska J. [The relationship between personality traits and burnout syndrome in teachers]. Psychol Wych. 1998;41(2):125-40. Polish.

46. Boyer W. Empathy Development in Teacher Candidates. Early Child Educ J. 2010;38:313-21, http://dx.doi. org/10.1007/s10643-010-0419-8.

47. Kliś M, Kossewska J. [Empathic abilities in teachers and students]. Psychol Wych. 1993;36(2):133-43. Polish.

48. Report: [Teachers: employment structure. PAP 2010] [cited 2012 May 18]. Available from URL: http://samorzad.infor.pl/sektor/zadania/oswiata/artykuly/452718,raport_nauczyciele_stan_i_struktura_zatrudnienia.html. Polish.

49. Wojciszke B. [Mood Regulation Scales]. In: MarszałWiśniewska M, Klonowicz T, Fajkowska-Stanik M, editors. [Psychology of individual differences]. Gdańsk: Gdansk Psychology Publisher; 2003. p. 163-79. Polish.

50. Pasikowski T. [Polish adaptation of Maslach Burnout Inventory]. In: Sęk H, editor. [Burnout. Causes and prevention]. Warszawa: Polish Scientific Publishers PWN; 2011. p. 13548. Polish.

51. Kaźmierczak M, Plopa M, Retowski S. [Empathic Sensitivity Scale]. Przegl Psychol. 2007;50(1):9-24. Polish.

52. Davis MH. Empathy: A social psychological approach. Boulder, CO: Westview Press; 1996.

53. Bedyńska S, Brzezicka A. [Statistical Signpost. Data analysis in social sciences on the examples from psychology. Practical guidebook]. Warszawa: Wydawnictwo SPSS Academica; 2007. Polish.
54. Stigler S. Fisher and the 5\% level. Chance. 2008;21(4):12, http://dx.doi.org/10.1007/s00144-008-0033-3.

55. Preacher KJ, Hayes AF. Asymptotic and resampling strategies for assessing and comparing indirect effects in multiple mediator models. Behav Res Methods. 2008;40(3):879-91, http://dx.doi.org/10.3758/BRM.40.3.879.

56. Cichocka A, Bilewicz M. [What is hidden in nonsignificant effests? Application of suppression analysis in social psychology]. Psychol Spol. 2010:5(14):191-8. Polish.

57. MacKinnon DP, Lockwood CM, Hoffman JM, West SG, Sheets V. A comparison of methods to test mediation and other intervening variable effects. Psychol Methods. 2002;7(1):83-104, http://dx.doi.org/10.1037/1082-989X. 7.1.83.

58. Hayes AF. Beyond Baron and Kenny: Statistical mediation analysis in the New Millennium. Commun Monogr. 2009;76(4):408-20, http://dx.doi.org/10.1080/03637 750903310360 .

59. Larsen RL. Toward a science of mood regulation. Psychol Inq. 2000;11(3):129-41.

60. Golińska L, Świętochowski W. [Temperamental and personality determinants of burnout in teachers]. Psychol Wych. 1998;41(5):385-98. Polish.

61. Hoffman ML. Empathy and Moral Development. Cambridge: Cambridge University Press; 2000.

62. Gross JJ. Antecedent - and response-focused emotion regulation: divergent consequences for experience, expression and physiology. J Pers Soc Psychol. 1998;74(1):224-37.

63. Gross JJ. Emotion regulation: Affective, cognitive and social consequences. Psychophysiology. 2002;39:281-91, http://dx. doi.org/10.1017.S0048577201393198.

This work is available in Open Access model and licensed under a Creative Commons Attribution-NonCommercial 3.0 Poland License - http://creativecommons.org/ licenses/by-nc/3.0/pl/deed.en. 